\title{
Direct Electron Transfer of Hemoglobin on Manganese III Oxide-Ag Nanofibers Modified Glassy Carbon Electrode
}

\author{
Masoud Negahdary, ${ }^{1}$ Gholamreza Mazaheri, ${ }^{1}$ Somyyeh Rad, ${ }^{1}$ \\ Mohammadreza Hadi, ${ }^{2}$ Roya Malekzadeh, ${ }^{3}$ Mohammad Mahdi Saadatmand, ${ }^{4}$ \\ Saeed Rezaei-Zarchi, ${ }^{3}$ Fariba Pishbin, ${ }^{1}$ and Mojdeh Khosravian-hemami ${ }^{2}$ \\ ${ }^{1}$ Department of Biology, Payam-e-Noor University, Tehran 7371719578, Iran \\ ${ }^{2}$ Department of Biology, Shahrekord University, Shahrekord, Iran \\ ${ }^{3}$ Department of Biology, Payam-e-Noor University, Taft, Iran \\ ${ }^{4}$ Young Researchers Club, Islamic Azad University, Yazd Branch, Yazd, Iran
}

Correspondence should be addressed to Masoud Negahdary, masoud_negahdary@yahoo.com

Received 30 December 2011; Accepted 4 February 2012

Academic Editor: Bahram Hemmateenejad

Copyright (c) 2012 Masoud Negahdary et al. This is an open access article distributed under the Creative Commons Attribution License, which permits unrestricted use, distribution, and reproduction in any medium, provided the original work is properly cited.

We investigated the electrochemical behavior of hemoglobin by glassy carbon electrode modified with $\mathrm{Mn}_{2} \mathrm{O}_{3}$ - $\mathrm{Ag}$ nanofibers. The $\mathrm{Mn}_{2} \mathrm{O}_{3}$ - Ag nanofibers were used as facilitator electron transfer between $\mathrm{Hb}$ and glassy-carbon-modified electrode. $\mathrm{The} \mathrm{Mn}_{2} \mathrm{O}_{3}-\mathrm{Ag}$ nanofibers are studied by scanning electron microscopy (SEM) and transmission electron microscopy (TEM). The hemoglobin showed a quasireversible electrochemical redox behavior with a formal potential of $-49 \mathrm{mV}$ (versus $\mathrm{Ag} / \mathrm{AgCl}$ ) in $0.1 \mathrm{M}$ potassium phosphate buffer solution at $\mathrm{pH}$ 7.0. The designed biosensor possesses good stability and reproducibility and achieves $95 \%$ of the steady-state current in less than five seconds.

\section{Introduction}

Hemoglobin is a remarkable molecular machine that uses motion and small structural changes to regulate its action. Oxygen binding at the four heme sites in hemoglobin does not happen simultaneously. Once the first heme binds oxygen, it introduces small changes in the structure of the corresponding protein chain. The main function of red blood cell is transfer of $\mathrm{O}_{2}$ from lungs to tissue and transfer of $\mathrm{CO}_{2}$ from tissue to lungs. To accomplish these functions, red cells have hemoglobin $(\mathrm{Hb})$. The $\mathrm{Hb}$ has iron in center of its structure [1]. The iron has important role in Hb structure [2]. We too used $\mathrm{Hb}$ in this project. Glassy carbon derives its name from exhibiting fracture behavior similar to glass, from having a disordered structure over large dimensions (although it contains a graphitic microcrystalline structure), and because it is a hard shiny material, capable of high polish [3-5]. Glassy carbon is particularly useful in electrochemical applications because of its low electrical resistivity, impermeability to gases, high chemical resistance, and because it has the widest potential range observed for carbon electrode. Glassy carbon was first prepared by Yamada and Sato in 1962 by the hight emperature pyrolysis of phenolic resin, and later by Davison who used cellulose as the starting material $[6,7]$. They concluded that glassy carbon consists of long microfibrils that twist, bend, and interlock to form interfibrillar bonds, and that these microfibrils are randomly oriented [8]. Because of the desire to impart selectivity to electrochemical reactions and to control electron transfer kinetics, several investigators have utilized adsorption or covalent bonding of catalysts to the glassy carbon surface. The intent of these modifications is to control the interaction of molecules and ions with the electrode surface [9]. Small fibers in the submicron range, in comparison with larger ones, are well known to provide better filter efficiency at the same pressure drop in the interception and inertial impaction regimes $[10,11]$. Previous researches shown such effect by assuming nonslip flow at fiber surface [12]. While smaller fiber size leads to higher-pressure drop, interception and inertial impaction efficiencies will increase faster, more than compensating for the pressure 
drop increase. Thus, in the particle size of interest, that is, from submicron and up, better filter efficiency can be achieved at the same pressure drop, or conversely, the same filter efficiency at lower pressure drop can be achieved with smaller fiber sizes. Polymeric nanofibers can be made using the electrospinning process, which has been described in the literature [13] and in patents [14]. Electrospinning uses an electric field to draw a polymer solution from the tip of a capillary to a collector. A voltage is applied to the polymer solution, which causes a jet of the solution to be drawn toward a grounded collector. The fine jets dry to form polymeric fibers, which can be collected on a web. The electrospinning process has been documented using a variety of fiberforming polymers $[15,16]$. By choosing a suitable polymer and solvent system, nanofibers with diameters in the range of 40-2000 nm can be made. PVP is a kind of polymers which is able to adsorb through many points of the molecule on the surface of steel, copper, and zinc and reduce the corrosion rate of the material [17-19]. PVPs are considered as food additives and, hence, their addition will not raise health concerns for treating RO water. However, the effect of the molecular weight of polyvinylpyrrolidone, its concentration, and temperature on the corrosion properties of $316 \mathrm{~L}$ stainless steel in reverse osmosis water were not evaluated.

\section{Material and Methods}

2.1. Electrospinning Nanofibers. Electrospinning is a process of applying a high-voltage electric field (several to tens of kilovolts) to generate electrically charged jets from polymer solutions or melts and further to produce polymer (nano) fibers. This technique is quite similar with the commercial process for drawing microscale fibers; however, it is more suitable for generating nanofibers, because the elongation can be accomplished by a contactless scheme through the application of an external electric field [20]. Generally, generation of porous surface on a bulk electrospinning nanofiber can be realized through two different ways. The first one is based on the selective removal of a component from nanofibers made of a composite or blend material, while the other one involved the use of phase separation of different polymers during electrospinning under the application of proper sinning parameters [16]. Both the pore size and the density are controllable by changing the parameters. For instance, in PLA/PVP electrospinning nanofibers, more porosity can be generated when the two materials are loaded in equal amounts comparing to the 11 corresponding products by different proportion of PLA/PVP. It can be attributed to the rapid-phase separation and solidification in the spinning jet [14-17]. PLA is contraction name of polylactic acid, and it is a thermoplastic polymer made from lactic acid and has mainly been used for biodegradable products, such as plastic bags and planting cups [18]. The PLA/PVP/nanofibers have been prepared by electrospinning [19]. It was found that the average diameter of the PLA/PVP/nanofibers lead fibers became larger, and the morphology of the fibers became finer with the content of PLA increasing. The formation of pores is also affected by the solvent vapor pressure and the humidity in atmosphere. The cooling effect that comes from rapid eva- poration of a highly volatile solvent might induce the polymers to separate into different phases in liquid jet. Because of evaporative cooling and condensation, water droplets could also be formed within the fibers to promote the formation of porous nanofibers [20-22]. The electrospun nanofibers exhibit several unique features, which enable the prevalent utilization of them. Because electrospinning is a continuous process without any contact force for elongation, the fibers can be as long as several kilometers and can be further assembled into a $3 \mathrm{D}$ mat with porous structure. At the same time, electrospun fibers can have a thinner diameter and surface-to-volume ratio, due to the presence of porous structure. In addition, due to the simple fabrication process and the diversity of suitable materials, the electrospinning technique and its resultant nanofiber product have attracted increasing attention. These properties potentiate the use of the electrospun nanofibers in various applications such as reinforced composites, nanofiber-based membranes, nanofiberbased support for enzyme, and catalyst [23-25].

2.2. Reagents. $\mathrm{Hb}$, manganese(II) nitrate tetrahydrate, and poly(vinylpyrrolidone) (PVP, MW $=1,300,000$ ) were purchased from Sigma. Silver nitrate and other materials were supplied by Merck. $0.1 \mathrm{M}$ phosphate buffer solutions with various $\mathrm{pH}$ values were prepared by mixing stock standard solutions of $\mathrm{Na}_{2} \mathrm{HPO}_{4}$ and $\mathrm{NaH}_{2} \mathrm{PO}_{4}$ and adjusting the $\mathrm{pH}$ values with $\mathrm{NaOH}$ and $\mathrm{H}_{3} \mathrm{PO}_{4}$ solution. All solutions used in the experiments were prepared with deionized water generated by a Barnstead water system.

2.2.1. Preparation of $\mathrm{Mn}_{2} \mathrm{O}_{3}-\mathrm{Ag} \quad$ Nanofibers. $44 \mathrm{wt} \%$ $\mathrm{Mn}\left(\mathrm{NO}_{3}\right)_{2}, 11 \mathrm{wt} \% \mathrm{AgNO}_{3}$, and $44 \mathrm{wt} \% \mathrm{PVP}$ were dissolved in DMF. The solution was kept under magnetic stirring for $2 \mathrm{~h}$ and then loaded into a plastic syringe equipped with a 23-gauge needle made of stainless steel. Electrospinning process was conducted at an applied voltage of $20 \mathrm{kV}$ with a feeding rate of $0.3 \mathrm{~mL} / \mathrm{h}$ and a collection distance of $15 \mathrm{~cm}$. The nanofibers were collected on aluminum foil and then calcined under air atmosphere at $500^{\circ} \mathrm{C}$ for $3 \mathrm{~h}$ for the degradation of PVP and the decomposition of $\mathrm{Mn}\left(\mathrm{NO}_{3}\right)_{2}$ and $\mathrm{AgNO}_{3}$ :

$$
\begin{gathered}
4 \mathrm{Mn}\left(\mathrm{NO}_{3}\right) \stackrel{\Delta}{\rightarrow} 2 \mathrm{Mn}_{2} \mathrm{O}_{3}+8 \mathrm{NO}_{2} \uparrow+\mathrm{O}_{2} \uparrow \\
2 \mathrm{AgNO}_{3} \stackrel{\Delta}{\rightarrow} 2 \mathrm{Ag}+2 \mathrm{NO}_{2} \uparrow+\mathrm{O}_{2} \uparrow
\end{gathered}
$$

Electrospinning is a process of applying a high-voltage electric field (several to tens of kilovolts) to generate electrically charged jets from polymer solutions or melts and further to produce polymer (nano) fibers. So, in this study, we used from this method to produce $\mathrm{Mn}_{2} \mathrm{O}_{3}$ - Ag nanofibers.

\subsubsection{Preparation of $\mathrm{Mn}_{2} \mathrm{O}_{3}-\mathrm{Ag}$-Nanofibers-Modified Glassy} Carbon Electrode. The most commonly used carbon-based electrode in the analytical laboratory is glassy carbon (GC). It is made by pyrolyzing a carbon polymer, under carefully controlled conditions, to a high temperature like $2000^{\circ} \mathrm{C}$. An intertwining ribbon-like material results with retention of high conductivity, hardness, and inertness. Glassy carbon electrode (GCE, dia. $3 \mathrm{~mm}$ ) was polished with $1 \mu \mathrm{m}$ and 
$0.05 \mu \mathrm{m}$ alumina slurries sequentially and then rinsed with DI water. After that, the electrode was sonicated in deionized water and finally dried under ambient conditions. To prepare the modified GCE, The $\mathrm{Mn}_{2} \mathrm{O}_{3}$-Ag nanofibers/glassy carbon electrode was placed into a fresh PBS including $5 \mathrm{mg} \mathrm{mL}$ $\mathrm{Hb}\left(\mathrm{pH} \mathrm{7.0,} 3\right.$ to $5^{\circ} \mathrm{C}$ ) for $8 \mathrm{~h}$. At the end, the modified electrode was washed in deionized water and placed in PBS $(\mathrm{PH}$ $7.0)$ at a refrigerator $\left(3\right.$ to $\left.5^{\circ} \mathrm{C}\right)$, before being employed in the electrochemical measurements as the working electrode.

2.2.3. Apparatus and Electrochemical Measurement. A JEOL $6335 \mathrm{~F}$ field-emission scanning electron microscope (SEM) was used to examine the morphology and the size of the asprepared nanofibers. More detailed morphology and selected area electron diffraction (SAED) patterns of $\mathrm{Mn}_{2} \mathrm{O}_{3}-\mathrm{Ag}$ nanofibers were obtained with a Tecnai T12 transmission electron microscope (TEM) operated at $120 \mathrm{kV}$. XRD pattern was obtained with Oxford diffraction XcaliburTM PX Ultra with ONYX detector to study the crystal structure of $\mathrm{Mn}_{2} \mathrm{O}_{3}$ $\mathrm{Ag}$ nanofibers measurements which were carried out with a potentiostat/galvanostat (Model 263A, EG\&G, USA) using a single compartment voltammetric cell, equipped with a platinum rod auxiliary electrode. All experiments were conducted using a three-electrode electrochemical cell $(10 \mathrm{~mL}$ volume with a working volume of $5 \mathrm{~mL}$ ), with a working electrode, an $\mathrm{Ag} / \mathrm{AgCl}$ reference electrode, and a platinum wire counter electrode. Electrochemical measurements were carried out with a potentiostat/galvanostat (Model 263A, EG\&G, USA) using a single compartment voltammetric cell, equipped with a platinum rod auxiliary electrode.

\section{Results and Discussion}

3.1. Characterization of $\mathrm{Mn}_{2} \mathrm{O}_{3}-\mathrm{Ag}$ Nanofibers. SEM was first employed to investigate the morphology of the $\mathrm{Mn}_{2} \mathrm{O}_{3}$ Ag nanofibers. Figure 2(a) presents a typical SEM image of electrospun precursory PVP- $\mathrm{Mn}\left(\mathrm{NO}_{3}\right)_{2}-\mathrm{AgNO}_{3}$ nanofibers. PVP was used for characterization of $\mathrm{Mn}_{2} \mathrm{O}_{3}-\mathrm{Ag}$ nanofibers, because PVP binds to polar molecules exceptionally well, owing to its polarity. This has led to its application in coatings for increase of photo quality in microscopic studies. The molecular structure of PVP can be observed in Figure 1. PVP is soluble in water and other polar solvents. When dry, it is a light flaky powder, which readily absorbs up to $40 \%$ of its weight in atmospheric water. In solution, it has excellent wetting properties and readily forms films. This makes it good as a coating or an additive to coatings. PVP is a branched polymer, that is, its structure is more complicated than linear polymer, but it too is in a two-dimensional plane. Moreover, because $\mathrm{Mn}_{2} \mathrm{O}_{3}-\mathrm{Ag}$ nanofibers have polar groups too, a good bind was created between this nanofiber and PVP.

After calcination, the as-prepared $\mathrm{Mn}_{2} \mathrm{O}_{3}-\mathrm{Ag}$ composite nanofibers (Figure 2(b)) exhibit a porous network structure, and their surfaces are no longer as smooth as the precursory nanofibers. Such feature endows the nanofibers with high surface-to-volume ratio, which could provide not only a large surface area for $\mathrm{Hb}$ loading but also a large interface for direct electron transfer of $\mathrm{Hb}$. As a comparison, the nanofibers prepared by single metal salt $\left(\mathrm{Mn}\left(\mathrm{NO}_{3}\right)_{2}\right)$ with PVP and

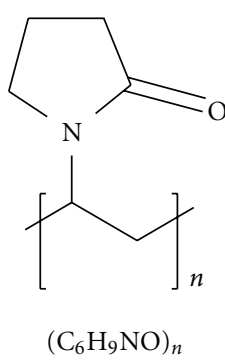

Figure 1: Molecular structure of polyvinylpyrrolidone (PVP).

its calcined product $\left(\mathrm{Mn}_{2} \mathrm{O}\right.$ nanofibers) are presented in Figures 2(c) and 2(d), respectively.

3.2. XRD Diffraction of $\mathrm{Mn}_{2} \mathrm{O}_{3}-\mathrm{Ag}$ Nanofibers. The composition and crystal structure were characterized by XRD (Figure 3). The XRD spectrum of $\mathrm{Mn}_{2} \mathrm{O}_{3}-\mathrm{Ag}$ nanofibers matches the combination of the standard spectrum of JCPDS 41-1442 $\left(\mathrm{Mn}_{2} \mathrm{O}_{3}\right)$ and JCPDS 04-0783 (Ag). The formation of face-centered cubic crystalline $\mathrm{Mn}_{2} \mathrm{O}_{3}$ is revealed by the diffraction peaks at $2 \theta$ values of $32.951,38.234,45.178$, $49.347,55.189$, and 65.806, corresponding to (111), (200), (220), (311), (222), and (400) crystal planes, respectively, while the diffraction peaks at $2 \theta$ values of $38.116,44.277$, and 64.426, which correspond to (111), (200), and (220) crystal planes, respectively, indicate the formation of cubic crystalline Ag.

3.2.1. Direct Electrochemistry of $\mathrm{Hb} / \mathrm{Mn}_{2} \mathrm{O}_{3}-\mathrm{Ag}$ Nanofibers/ GCE. Cyclic voltammetry (CV) was used to characterize the modification of electrodes. The cyclic voltammograms (CVs) of different modified electrodes were obtained in 0.1 M PBS with pH 7.0. No redox peak is observed for the CVs of bare GC electrode. Compared with bare GC electrode, the background current of $\mathrm{Mn}_{2} \mathrm{O}_{3}$-Ag-nanofibers-modified electrode is apparently larger, which indicates that the effective electrode surface area is significantly enhanced by use of $\mathrm{Mn}_{2} \mathrm{O}_{3}$-Ag nanofibers to modify the electrode. However, the CVs of $\mathrm{Hb} / \mathrm{Mn}_{2} \mathrm{O}_{3}-\mathrm{Ag}$ nanofibers/GC electrode give a pair of well-defined redox peaks at $-75 \mathrm{mV}$ at scan rate of $100 \mathrm{mV} / \mathrm{s}$, characteristic of heme $\mathrm{Fe}(\mathrm{III}) / \mathrm{Fe}$ (II) redox couples of $\mathrm{Hb}$, suggesting that direct electron transfer has been achieved between $\mathrm{Hb}$ and modified electrode. The electron transfer of the proteins, at the bare electrodes is very slow so that the redox peak of proteins can usually be observed. Figure $4(\mathrm{a})$ shows a cyclic voltammogram $(\mathrm{CV})$ of the bare glassy carbon electrode. Figure 4(b) shows a cyclic voltammogram of $\mathrm{Hb} / \mathrm{Mn}_{2} \mathrm{O}_{3}$-Ag nanofibers/glassy carbon electrode in $0.1 \mathrm{M}$ phosphate buffer at $\mathrm{pH}$ 7.0. The Hb showed quasireversible electrochemical behavior with a formal potential of $-49 \mathrm{Mv}$ (versus $\mathrm{Ag} / \mathrm{AgCl}$ ); cathodic and anodic peaks were not observed using the bare graphite electrode. This shows that $\mathrm{Mn}_{2} \mathrm{O}_{3}-\mathrm{Ag}$ nanofibers act as a facilitator of electron transfer from the redox species of $\mathrm{Hb}$ to the electrode surface and vice versa. These results are in line with the previous work that explains the behavior of nanoparticles as the facilitators of electron transfer. 


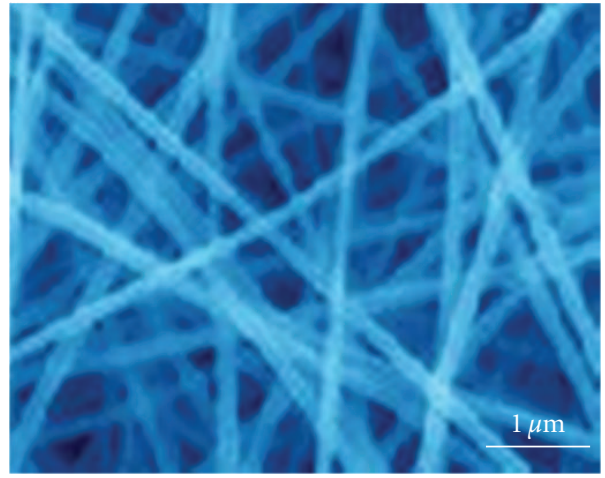

(a)

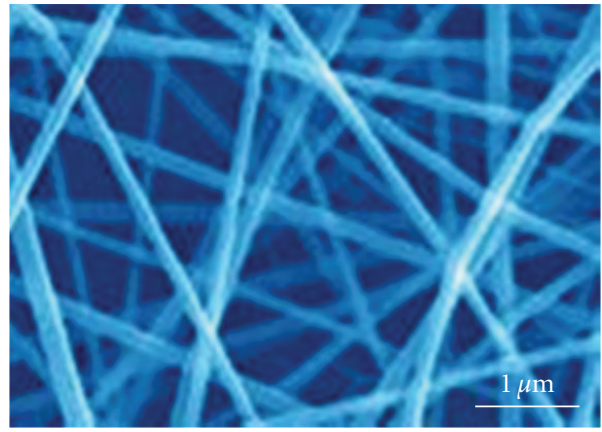

(c)

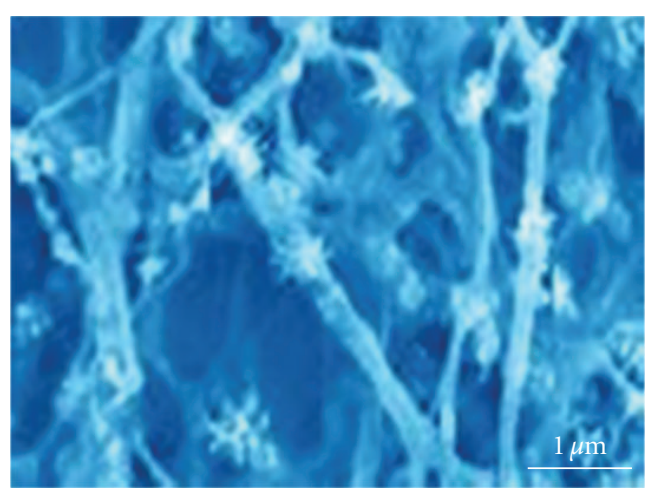

(b)

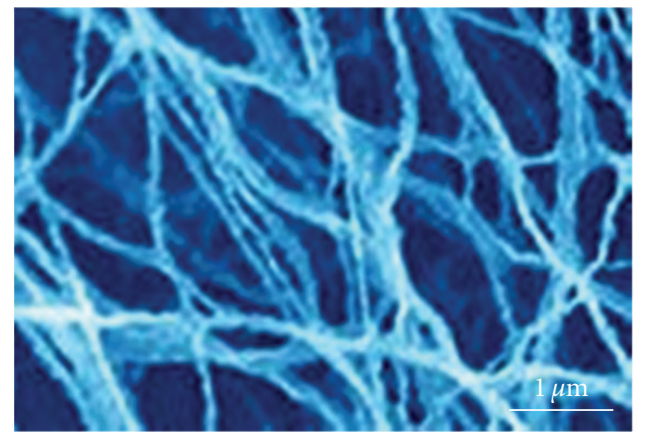

(d)

Figure 2: SEM images of (a) PVP-Mn( $\left.\mathrm{NO}_{3}\right)_{2}-\mathrm{AgNO}_{3}$ nanofibers, (b) $\mathrm{Mn}_{2} \mathrm{O}_{3}$-Ag nanofibers, (c) PVP-Mn( $\left.\mathrm{NO}_{3}\right)_{2}$ nanofibers, and (d) $\mathrm{Mn}_{2} \mathrm{O}_{3}$ nanofibers, respectively.

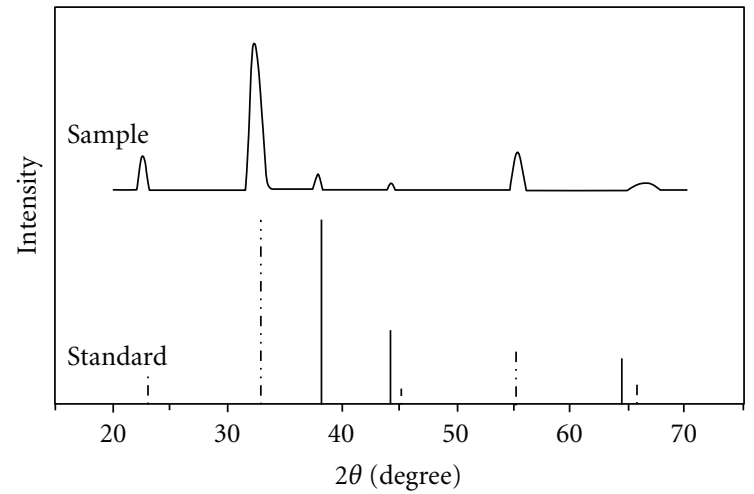

FIGURE 3: XRD patterns for the standard values of JCPDS 41-1442 ( $\mathrm{Mn}_{2} \mathrm{O}_{3}$, dashed line), JCPDS 04-0783 (Ag, solid line), and the asprepared porous $\mathrm{Mn}_{2} \mathrm{O}_{3}$ - $\mathrm{Ag}$ nanofibers.

In Figure 4(a), one sees cyclic voltammogram for bare and modified glassy carbon electrode in 50, 100, 200, 300, 400 , and 500 scan rates. These data showed that the $\mathrm{Mn}_{2} \mathrm{O}_{3}$ $\mathrm{Ag}$ nanofibers were successfully assembled on the glassy carbon electrode surface. The redox peak currents increase linearly with the square root of the scan rate. With an increasing scan rate, the anodic peak potential of adsorbed $\mathrm{Hb}$ shifted to a more positive value, while the cathodic peak current shifted in a negative direction. The redox peak currents were proportional to the scan rate (Figure 5); thus, the electrode

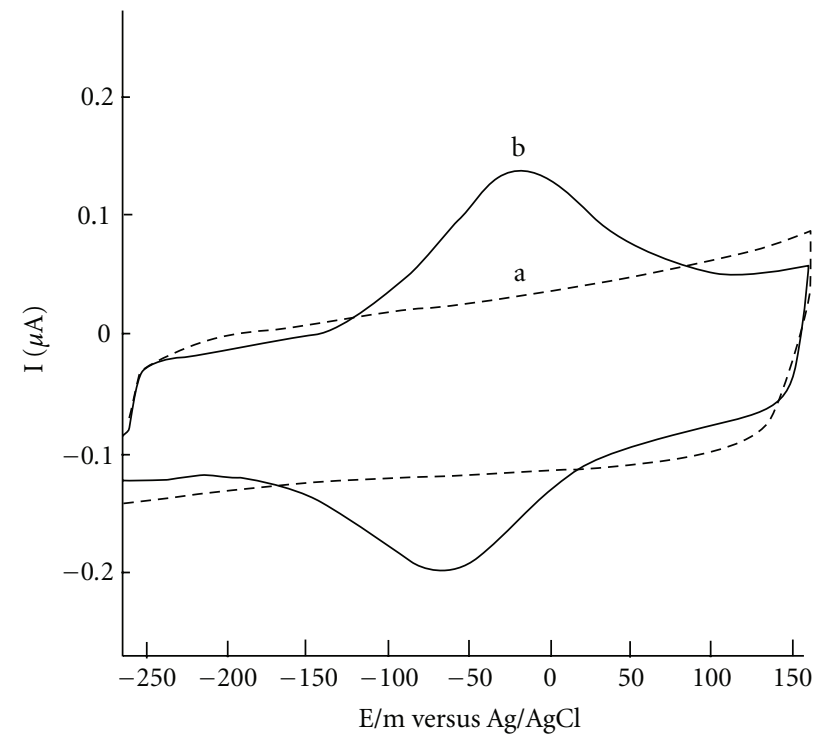

Figure 4: Cyclic voltammograms, using (a) bare glassy carbon electrode in $0.1 \mathrm{M}$ phosphate buffer solution and (b) $\mathrm{Hb} / \mathrm{Mn}_{2} \mathrm{O}_{3}$ Ag nanofibers/glassy carbon electrode in $0.1 \mathrm{M}$ phosphate buffer solution (scanrate: $100 \mathrm{mV} \mathrm{s}^{-1}$ ).

reaction was typical of the surface-controlled quasireversible process. One can see in Figure 5(b) the dependence of the anodic and cathodic peak currents on the scan rates that the 


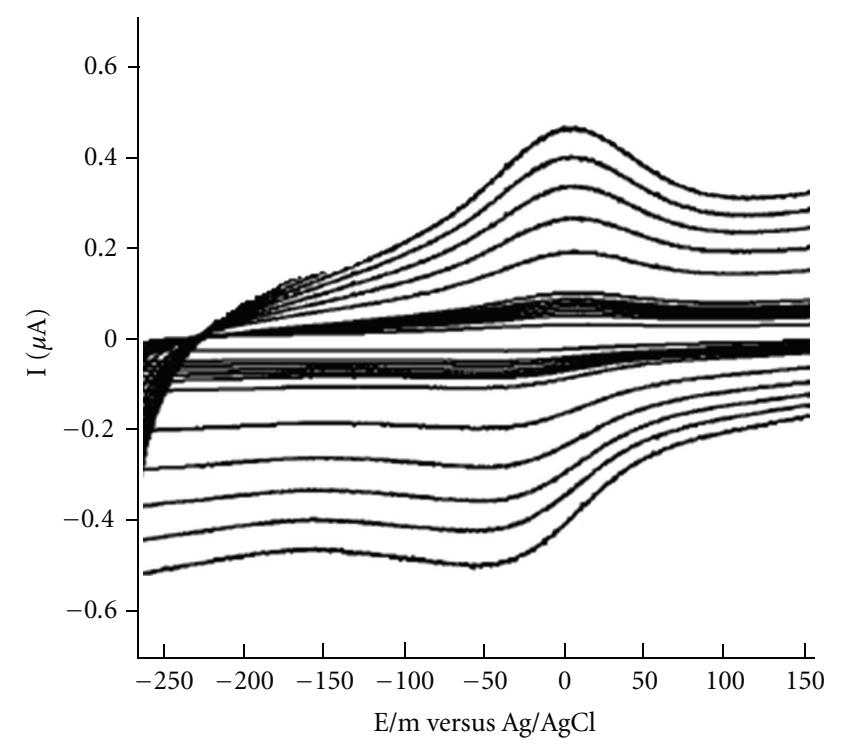

(a)

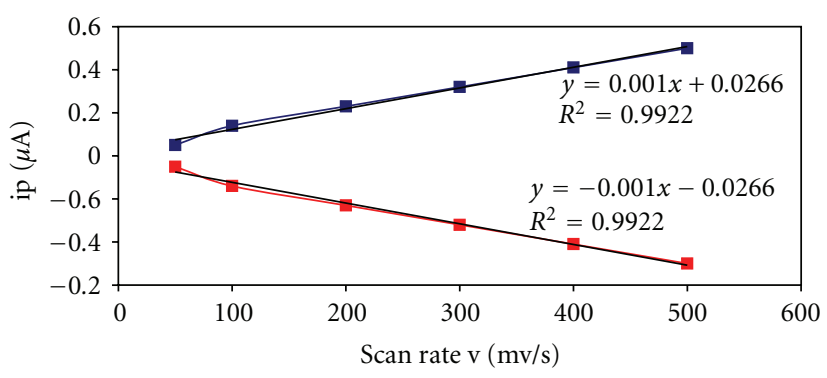

(b)

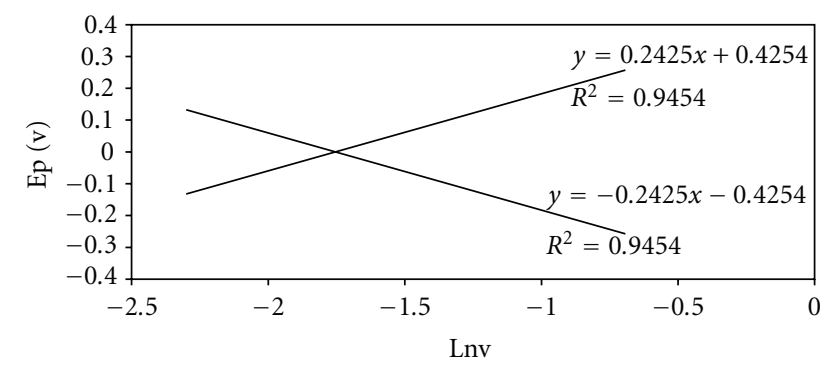

(c)

Figure 5: (a) Typical cyclic voltammograms of $\mathrm{Hb} / \mathrm{Mn}_{2} \mathrm{O}_{3}-\mathrm{Ag}$ nanofibers/glassy carbon electrode at different scan rates. The voltammograms (from inner to outer) designate scan rates of 50,100, 200,300,400, and $500 \mathrm{mV} \mathrm{s}^{-1}$, respectively. (b) Dependence of the anodic and cathodic peak currents on the scan rates the red line is cathodic and the blue line is anodic. (c) Relationship between the peak potential ( $E_{\mathrm{p}}$ ) and the natural $\log$ arithm of scan rate $(\ln v)$ for $\mathrm{Hb} / \mathrm{Mn}_{2} \mathrm{O}_{3}-\mathrm{Ag}$ nanofibers/glassy carbon electrode. All the data were obtained at $\mathrm{pH} 7.0$ and in $0.1 \mathrm{M}$ phosphate buffer solution.

red line is cathodic and the blue line is anodic. The kinetics of the heterogeneous electron transfer was analyzed using the model of Laviron [9]. The plot of cathodic peak potentials versus the logarithm of scan rates gave a charge transfer coefficient $\alpha$ of 0.52 . For scan rates from 50 to $500 \mathrm{mV} / \mathrm{s}$, the electron transfer rate constant $k_{s}$ was estimated to be (1.9) $\mathrm{s}^{-1}$. These statements discussed below indicate that $\mathrm{Hb}$ is strongly adsorbed onto the surface of modified electrode. As could be seen in Figure 5(c), in the range from 200 to $500 \mathrm{mV} \mathrm{s}^{-1}$, the catholic peak potential $\left(E_{\mathrm{pc}}\right)$ changed linearly versus $\ln v$ with a linear regression equation of $y=-0.2425 x-0.4254$, $R^{2}=0.945$, according to the following equation [26-28],

$$
E_{\mathrm{p}}=E^{\circ \prime}+\frac{R T}{\alpha n F}-\frac{R T}{\alpha n F} \ln v^{\prime},
$$

where $\alpha$ is the cathodic electron transfer coefficient, $n$ is the number of electrons, $R, T$, and $F$ are gas, temperature, and Faraday constant, respectively $\left(R=8.314 \mathrm{~J} \mathrm{~mol}^{-1} \mathrm{~K}^{-1}, F=\right.$ $96493 \mathrm{C} / \mathrm{mol}, T=298 \mathrm{~K}$ ), and $\alpha n$ is calculated to be 0.52 . Given $0.3<\alpha<0.7$ in general [9], it could be concluded that $n=1$ and $\alpha=0.52$. From the width of the peak at midheight and low scan rate, we can also obtain $n=1$ [9]. Therefore, the redox reaction between $\mathrm{Hb}$ and modified graphite electrode is a single electron transfer process. In order to calculate the value of apparent heterogeneous electron transfer rate constant $\left(k_{s}\right)$, the following equation was used [26-28]:

$$
\begin{aligned}
\log k_{s}= & \alpha \log (1-\alpha)+(1-\alpha) \log \alpha-\log \left(\frac{R T}{n F v}\right) \\
& -\alpha(1-\alpha) \frac{n F \Delta E_{\mathrm{p}}}{2.3 R T} .
\end{aligned}
$$

The $k_{s}$ was calculated to be $1.90 \mathrm{~s}^{-1}$. Moreover, this $k_{s}$ indicates that transfer of electron is good and fast in Hb-modified glassy carbon electrode.

3.2.2. Design a Hydrogen Peroxide Biosensor. The designed biosensor is introduced as a hydrogen biosensor because it has oxidation and reduction reactions in $\mathrm{Hb}$; when $\mathrm{Fe}^{2+}$ changes to $\mathrm{Fe}^{3+}$, the oxidation reaction occurred, and when $\mathrm{Fe}^{3+}$ changes to $\mathrm{Fe}^{2+}$, the reduction reaction occurred. The 


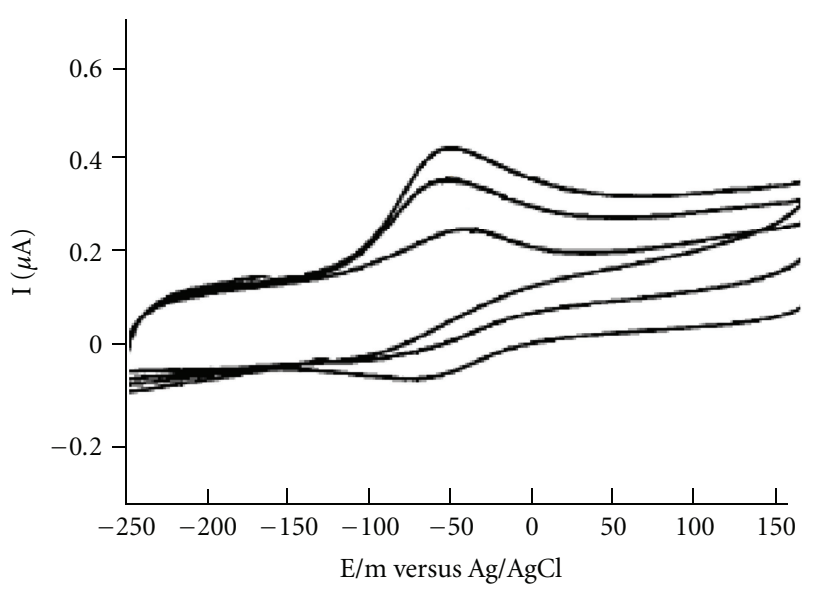

(a)

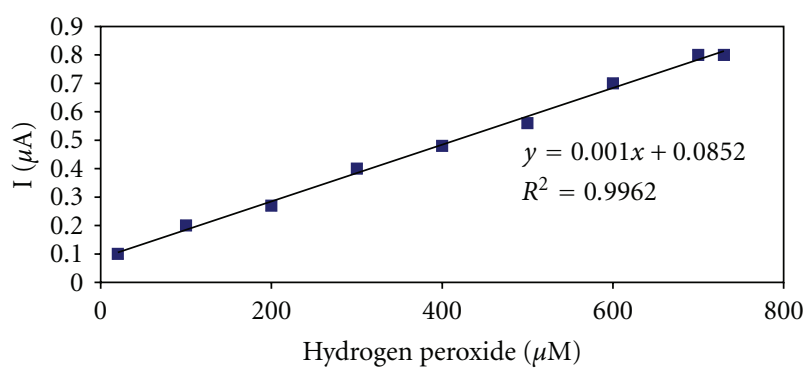

(b)

Figure 6: (a) Cyclic voltammograms obtained at an $\mathrm{Hb} / \mathrm{Mn}_{2} \mathrm{O}_{3}-\mathrm{Ag}$ nanofibers/glassy carbon electrode in $50 \mu \mathrm{M}$ phosphate buffer solution ( $\mathrm{pH}$ 7.0) for different concentrations and (b) the relationship between cathodic peak current of $\mathrm{Hb}$ and different concentrations of $\mathrm{H}_{2} \mathrm{O}_{2}$ (scan rate: $100 \mathrm{mV} \mathrm{s}^{-1}$ ).

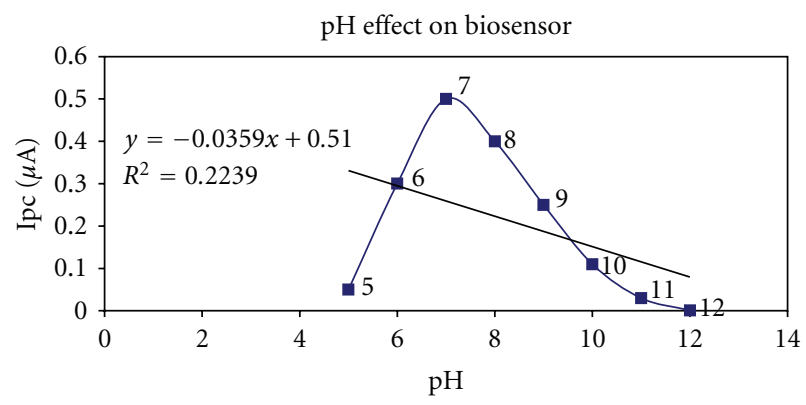

Figure 7: Dependence of the current response of $\mathrm{Hb} / \mathrm{Mn}_{2} \mathrm{O}_{3}-\mathrm{Ag}$ nanofibers/GC electrode to $50.0 \mu \mathrm{M} \mathrm{H}_{2} \mathrm{O}_{2}$ on the $\mathrm{pH}$ of buffer solutions.

reduction state is an important matter for designing hydrogen peroxide biosensors [29].

The electrocatalytic reactivity of $\mathrm{Hb} / \mathrm{Mn}_{2} \mathrm{O}_{3}$ - $\mathrm{Ag}$ nanofibers/GC electrode toward $\mathrm{H}_{2} \mathrm{O}_{2}$ was investigated by CV. Figure 6 displays the cyclic voltammograms obtained for the hydrogen peroxide biosensor in PBS (pH 7.0) containing varied concentration of $\mathrm{H}_{2} \mathrm{O}_{2}$ in the absence of oxygen. The catalytic reduction of hydrogen peroxide at the biosensor can be seen clearly in Figure 5. With the addition of $\mathrm{H}_{2} \mathrm{O}_{2}$, the reduction peak current increases obviously, while the oxidation peak current decreases (Figures 6(a) and 6(b)), indicating a typical electrocatalytic reduction process of $\mathrm{H}_{2} \mathrm{O}_{2}$. However, no similar cathodic peak corresponding to the reduction of $\mathrm{H}_{2} \mathrm{O}_{2}$ can be observed at bare GC, $\mathrm{Mn}_{2} \mathrm{O}_{3}-\mathrm{Ag}$ nanofibers/GC electrode under the same condition, so it can be concluded that $\mathrm{Hb}$ immobilized on $\mathrm{Mn}_{2} \mathrm{O}_{3}-\mathrm{Ag}$ nanofibers/GC electrode shows good catalytic activity toward hydrogen peroxide [19]. Figure 6 shows the sensor response. The sensor was found to have sensitivity in the range of 20 to $700 \mu \mathrm{M}$ based upon the mean of the slope found from the points on the response curve. As can be observed, the sensor response shows good linearity in this range. The correlation factor, $R^{2}$, was found to be 0.9962 .

3.3. Influence of $p H$ and Applied Potential on Biosensor Response. In order to obtain an efficient biosensor for $\mathrm{H}_{2} \mathrm{O}_{2}$, the influence of $\mathrm{pH}$ and applied potential on the response of $\mathrm{Hb} / \mathrm{Mn}_{2} \mathrm{O}_{3}-\mathrm{Ag}$ nanofibers/GC electrode were investigated. The change of chronoamperometric current with the $\mathrm{pH}$ under constant hydrogen peroxide concentration $(50.0 \mu \mathrm{M})$ is shown in Figure 7. As can be seen, the maximum response appears at $\mathrm{pH} 7.0$. So the buffer solution of $\mathrm{pH} 7.0$ was selected for experiments. This designed biosensor possesses good stability and reproducibility and achieves $95 \%$ of the steadystate current in less than $5 \mathrm{~s}$.

\section{Conclusion}

A new biosensor for $\mathrm{H}_{2} \mathrm{O}_{2}$ was prepared based on $\mathrm{Hb}$ / $\mathrm{Mn}_{2} \mathrm{O}_{3}-\mathrm{Ag}$ nanofibers/glassy carbon electrode. $\mathrm{Hb}$ retained well in $\mathrm{Mn}_{2} \mathrm{O}_{3}$ - $\mathrm{Ag}$ nanofibers/GCE, which combined the utilities of $\mathrm{Mn}_{2} \mathrm{O}_{3}-\mathrm{Ag}$ nanofibers facilitating the electron transfer. At $\mathrm{Hb} / \mathrm{Mn}_{2} \mathrm{O}_{3}-\mathrm{Ag}$ nanofibers/GCE, the cyclic voltammogram exhibits a pair of redox peaks corresponding to a surface-controlled electrode process with a single-proton transfer. The designed biosensor displays a high affinity and sensitivity to $\mathrm{H}_{2} \mathrm{O}_{2}$. The sensor shows good reproducibility and stability.

\section{References}

[1] F. Davis and S. P. J. Higson, "Biofuel cells-recent advances and applications," Biosensors and Bioelectronics, vol. 22, no. 7, pp. 1224-1235, 2007.

[2] M. C. Potter, "Electrical effects accompanying the decomposition of organic compounds," Proceedings of the Royal Society, vol. 84, pp. 260-276, 1912.

[3] A. T. Yahiro, S. M. Lee, and D. O. Kimble, "Bioelectrochemistry. I. Enzyme utilizing bio-fuel cell studies," Biochimica et Biophysica Acta, vol. 88, no. 2, pp. 375-383, 1964.

[4] M. T. Sulak, O. Gökdoğan, A. Gülce, and H. Gülce, "Amperometric glucose biosensor based on gold-deposited polyvinylferrocene film on Pt electrode," Biosensors and Bioelectronics, vol. 21, no. 9, pp. 1719-1726, 2006.

[5] R. A. Bullen, T. C. Arnot, J. B. Lakeman, and F. C. Walsh, "Biofuel cells and their development," Biosensors and Bioelectronics, vol. 21, no. 11, pp. 2015-2045, 2006.

[6] K. G. Lim and G. T. R. Palmore, "Microfluidic biofuel cells: the influence of electrode diffusion layer on performance," Biosensors and Bioelectronics, vol. 22, no. 6, pp. 941-947, 2007. 
[7] A. Heller, "Miniature biofuel cells," Physical Chemistry Chemical Physics, vol. 6, no. 2, pp. 209-216, 2004.

[8] Y. Kamitaka, S. Tsujimura, N. Setoyama, T. Kajino, and K. Kano, "Fructose/dioxygen biofuel cell based on direct electron transfer-type bioelectrocatalysis," Physical Chemistry Chemical Physics, vol. 9, no. 15, pp. 1793-1801, 2007.

[9] S. Rezaei-Zarchi, M. Negahdary, M. Doroudian et al., "Direct electron transfer of Myoglobin on nickel oxide Nanoparticles modified graphite electrode," Advances in Environmental Biology, vol. 5, no. 10, pp. 3241-3248, 2011.

[10] J. Wang and M. Musameh, "Carbon nanotube/Teflon composite electrochemical sensors and biosensors," Analytical Chemistry, vol. 75, no. 9, pp. 2075-2079, 2003.

[11] K. Wu, J. Fei, and S. Hu, "Simultaneous determination of dopamine and serotonin on a glassy carbon electrode coated with a film of carbon nanotubes," Analytical Biochemistry, vol. 318, no. 1, pp. 100-106, 2003.

[12] X.-H. Zhang and S.-F. Wang, "Determination of ethamsylate in the presence of catecholamines using 4-amino-2-mercaptopyrimidine self-assembled monolayer gold electrode," Sensors and Actuators, B, vol. 104, no. 1, pp. 29-34, 2005.

[13] J. X. Wang, X. W. Sun, A. Wei et al., "Zinc oxide nanocomb biosensor for glucose detection," Applied Physics Letters, vol. 88, no. 23, Article ID 233106, 2006.

[14] Y. Ding, Y. Wang, L. Su, M. Bellagamba, H. Zhang, and Y. Lei, "Electrospun $\mathrm{Co}_{3} \mathrm{O}_{4}$ nanofibers for sensitive and selective glucose detection," Biosensors and Bioelectronics, vol. 26, no. 2, pp. 542-548, 2010.

[15] J. Rubio Retama, E. López Cabarcos, D. Mecerreyes, and B. López-Ruiz, "Design of an amperometric biosensor using polypyrrole-microgel composites containing glucose oxidase," Biosensors and Bioelectronics, vol. 20, no. 6, pp. 1111-1117, 2004.

[16] X. Lu, J. Zhou, W. Lu, Q. Liu, and J. Li, "Carbon nanofiberbased composites for the construction of mediator-free biosensors," Biosensors and Bioelectronics, vol. 23, no. 8, pp. 12361243, 2008.

[17] A. J. Amalraj, M. Sundaravadivelm, A. P. P. Regis, and S. Rajendran, "Corrosion inhibition by polyvinylpyrrolidone," in Proceedings of the 9th European Symposium on Corrosion Inhibitors, p. 407, 2000.

[18] A. A. Gürten, M. Erbil, and K. Kayakirilmaz, "Effect of polyvinylpyrrolidone on the corrosion resistance of steel," Cement and Concrete Composites, vol. 27, no. 7-8, pp. 802-808, 2005.

[19] Y. Jianguo, W. Lin, V. Otieno-Alego, and D. P. Schweinsberg, "Polyvinylpyrrolidone and polyethylenimine as inhibitors for the corrosion of a low carbon steel in phosphoric acid," Corrosion Science, vol. 37, no. 6, pp. 975-985, 1995.

[20] K. Oksman, M. Skrifvars, and J. F. Selin, "Natural fibres as reinforcement in polylactic acid (PLA) composites," Composites Science and Technology, vol. 63, no. 9, pp. 1317-1324, 2003.

[21] J. Xu, J. Zhang, W. Gao, H. Liang, H. Wang, and J. Li, "Preparation of chitosan/PLA blend micro/nanofibers by electrospinning," Materials Letters, vol. 63, no. 8, pp. 658-660, 2009.

[22] T. W. Ebbesen and P. M. Ajayan, "Large-scale synthesis of carbon nanotubes," Nature, vol. 358, no. 6383, pp. 220-222, 1992.

[23] Y. B. Vassilyev, O. A. Khazova, and N. N. Nikolaeva, "Kinetics and mechanism of glucose electrooxidation on different electrode-catalysts. Part II. Effect of the nature of the electrode and the electrooxidation mechanism," Journal of Electroanalytical Chemistry, vol. 196, no. 1, pp. 127-144, 1985.

[24] A. Gorman, A. McGowan, and T. G. Cotter, "Role of peroxide and superoxide anion during tumour cell apoptosis," FEBS Letters, vol. 404, no. 1, pp. 27-33, 1997.
[25] Z. Zhuang, X. Su, H. Yuan, Q. Sun, D. Xiao, and M. M. F. Choi, "An improved sensitivity non-enzymatic glucose sensor based on a $\mathrm{CuO}$ nanowire modified Cu electrode," Analyst, vol. 133, no. 1, pp. 126-132, 2008.

[26] A. J. Bard and L. R. Faulkner, "Electrochemical methods," in Fundamentals and Applications, p. 241, John Wiley \& Sons, New York, NY, USA, 2nd edition, 2001.

[27] E. Laviron, "General expression of the linear potential sweep voltammogram in the case of diffusionless electrochemical systems," Journal of Electroanalytical Chemistry, vol. 101, no. 1, pp. 19-28, 1979.

[28] E. Laviron, "The use of linear potential sweep voltammetry and of a. c. voltammetry for the study of the surface electrochemical reaction of strongly adsorbed systems and of redox modified electrodes," Journal of Electroanalytical Chemistry, vol. 100, no. 1-2, pp. 263-270, 1979.

[29] R. Banerjee and R. Cassoly, "Preparation and properties of the isolated $\alpha$ and $\beta$ chains of human hemoglobin in the ferri state. Investigation of oxidation-reduction equilibria," Journal of Molecular Biology, vol. 42, no. 2, pp. 337-349, 1969. 


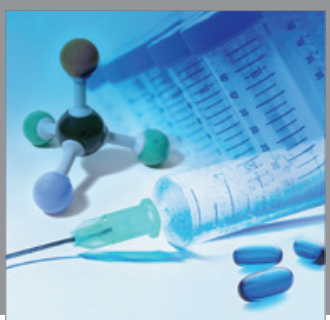

International Journal of

Medicinal Chemistry

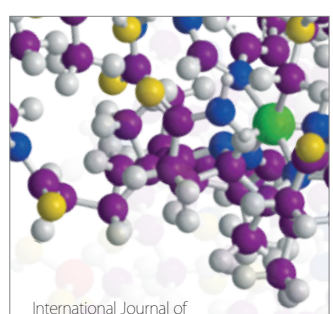

Carbohydrate Chemistry

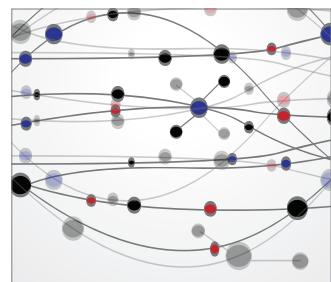

The Scientific World Journal
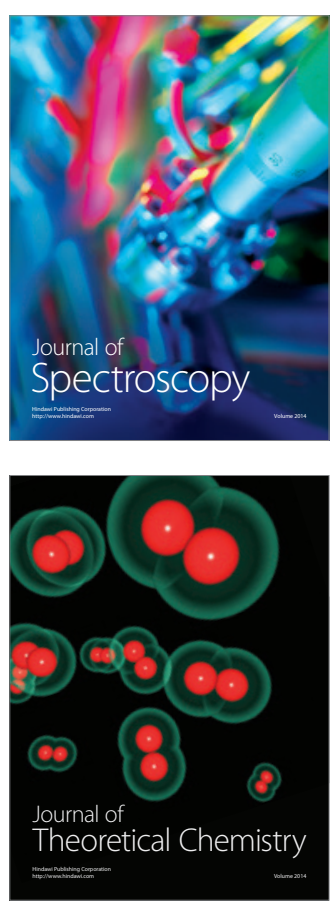
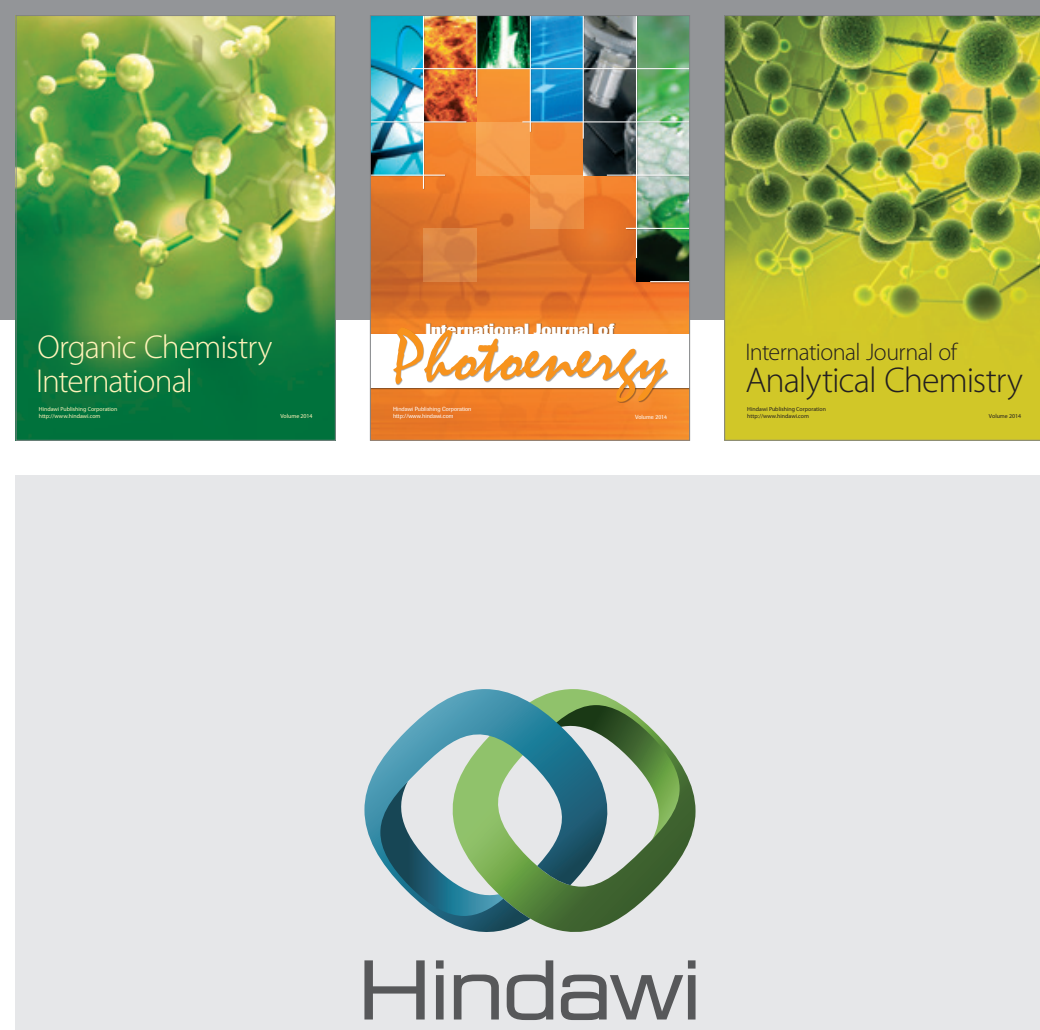

Submit your manuscripts at

http://www.hindawi.com
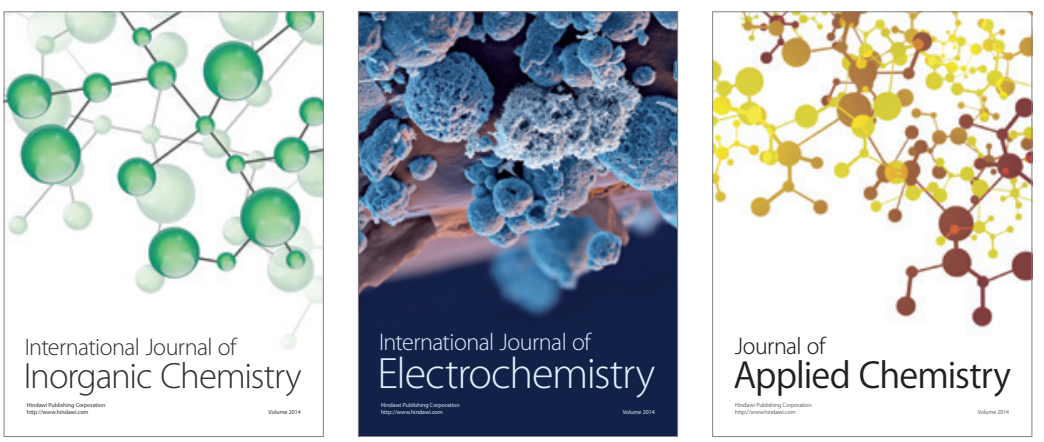

Journal of

Applied Chemistry
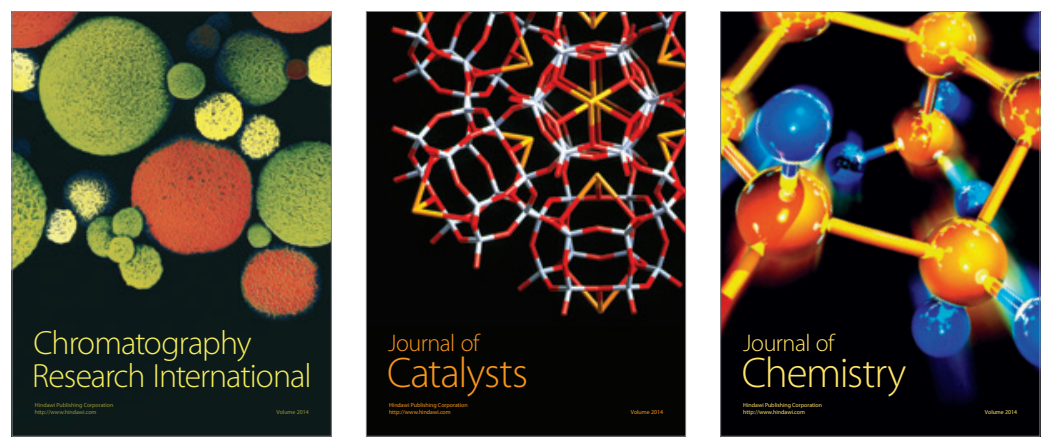
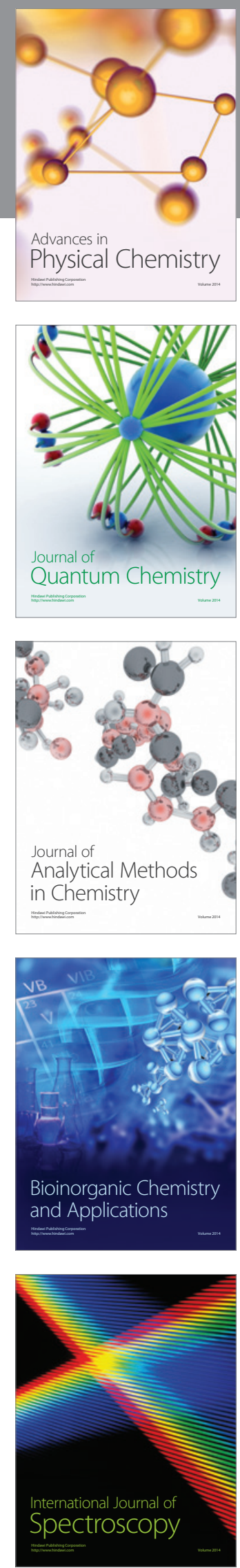